\title{
ENSAYO HISTÓRICO SOBRE LA GÉNESIS DE LA SUBLEVACIÓN DE LA MARINERÍA EN CHILE DEL AÑO 1931
}

\author{
HISTORIC ESSAY ON THE GENESIS OF SEAMANSHIP \\ REVOLT IN CHILI ON THE YEAR 1931
}

\author{
SANDRINO VERGARA PAREDES**
}

\section{RESUMFN}

El siguiente articulo señala que los argumentos presentados comúnmente por la historiografia para explicar ei origen de la insurrección nival de 1931, están incompletos. Generalmente a esta se le atribuyen cassas externas, tanto políticas como económicas, pero este estudio postula que esas motivaciones son superficiales, ya que una crisis política o una rebaja en los sueldos no bastan para levantar a una institución armada perfectamente organizada y disciplinada. Aquí se afirma que el principal factor que produjo la sublevación fue interno y estuvo representado por la pérdida de ta moral militar en las fuerzas armadas, debido al rompimiento de ciertos valores fundamentales en la vida militar como son el principio de autoridad a través de la jerarquia, la confianza y el respeto entre los mandos y sus subalternos.

Palabras clave: Sublevacion de la Marineria, Septiembre de 1931, Causas, Moral Militar.

\section{ABSTRACT}

The following article it indicates that the arguments presented commonly by the historiography to explain the origin of the naval insurrection of 1931, are incomplete. Generally he is assumed to this one by external, both political and economic reasons, but this study postulates that these motivations are superficial, since a political crisis or a reduction in the salaries are not enough to raise to an armed perfectly organized institution and discipline. Here one affirms that the principal factor that produced the revolt was internal and was represented by the loss of the military morality in the srmed forces, due to the breach of certain fundamental values in the military life since they are the principle of authority across the hierarchy, the confidence and the respect between the controls and his secondary ones.

Keywords: Revolt of the Seamanship, September, 1931, Reasons, Military Mulberry tree (Morality).

\section{INTRODUCCIÓN}

Debemos dejar claro primeramente que en general la historia y estos acontecimientos no son la excepción, tienen un origen multicausal, pero para el efecto didáctico de comprender la temática, se han abordado en forma separada las diversas hipótesis que existen en la historiografía para explicar las causas que provocaron el levantamiento de las tripulaciones del año 1931 y luego postular cual fue el origen de este. En este caso se encuentran tres teorías principales.

Una señala que el movimiento tuvo un origen político externo, ajeno a las tradiciones de la armada, culpándose principalmente a los "comités revolucionarios" opositores al general Ibáñez que se encontraban en Europa y también al partido comunista. 1

- Este articulo corresponde a un resumen del capitulo 11 de le Tesis de Pregrado.

*. Profesor de Historia y Geografia por la Universidad de Concepción. E-mail sandrinovergaraepudec.d

1 Ademas de los "comités revolucionarios" y los comunistas, fambién se culpabilizó a Alessandri e lbảnez como responsables de la sublevación para a traves de ella llegar al poder nuevamente. Ricardo Donsso menciona que cuando el vicepresidente Truco, citó a una "reunión de notables" a las 23:30 del martes 1' de septiembre de 1931, para analizar el levantamiento de las tripulaciones de la armada, y se irvitu al "Leán de Tarapaca", fue sólo "con el animo de descubrir sus propósitos".

Esta "posible" participación de Alessandri a lo menos en forma indirecta no hay que descartarla de plano, yar que es muy probable que el lidet nominal de la sublevacion, el suboficial mayor Ernesto Gonzales Brion, ent septiembre de 1931 haya sido alessandrista, o a lo menos simpatizara con este, pues al parecer, el con el "león de Tarapaca" se conocieron en Europa mientras el "Latorre" se encontraba en los astilleros britanicos repotenciandose. Como evidencia de esta cercania, esta el hecho de que durante el segundo gobjerno de Arturo Alessandri, Gonzales Brion fue nombrado diplamático en México y más tarde prefecto de la policia de investiggaciones. 
Otra hipótesis habla de que fue una sublevación causada por motivos exclusivamente económicos, debido a las rebajas de sueldos, y la última señala que este fue un movimiento "de clase", si es que se puede utilizar el término en las fuerzas armadas, entre la gente de mar de la armada y los suboficiales del ejército, donde a través del levantamiento buscaron un mejoramiento no sólo de las paupérrimas condiciones económicas que los aquejaban, sino en general de su situación postrada, como aspirar a una buena ley de retiros, o mejorar el frecuente mal trato de parte de los oficiales hacia ellos. Esta era una especie de oportunidad histórica de llegar al poder, como la que tuvieron los generales y almirantes en septiembre de 1924, y luego los oficiales jóvenes en enero de 1925.

\section{SITUACIÓN POLÍTICA}

Para resolver el problema hay que entender previamente el contexto que se vivia en ese entonces y por ello debemos señalar que desde el 5 de septiembre de 1924, el país entraba a una fase donde el poder paso a manos de los militares, y más puntualmente desde el 23 de enero de 1925, a manos de un sólo hombre, el entonces comandante y futuro general Carlos Ibáfiez del Campo, quien gobernó el pais a través de su influencia como ministro de guerra del retornado presidente Alessandri y ministro de interior más tarde del mandatario don Emiliano Figueroa Larraín, para luego llegar a ser presidente de la Republica propiamente tal, hasta el 26 de julio de 1931, cuando renuncia por las crisis que el país vivía y para evitar un derramamiento de sangre. Su gobierno se caracterizó por ser reformista, modernizador y a la vez autoritario. Fue especialmente esto último lo que le ganó muchos adversarios tanto políticos como militares, algunos de los cuales lo habían acompañado en los movimientos de septiembre del 24 y enero del 25, como el coronel Marmaduque Grove Vallejos, quien fuera luego fundador de partido socialista de Chile.

Estos adversarios dentro del concierto americano se organizaron en Buenos Aires, dando forma a un comité revolucionario ${ }^{2}$ y es desde allá, de Argentina, de donde salió con dirección a Concepción en Chile, el recordado "Avión Rojo", que traía al general Bravo, a Grove, al ex senador Salas Romo, a Pedro León Ugalde, al profesor Víctor Fuentes y a José Luís Sánchez Pizarro ${ }^{3}$ con la intención de sublevar la III división de ejército y derrocar a lbañez, lo que terminó en un aparatoso fracaso y con la mayor parte de los conspiradores tras las rejas o relegados.

Otros adversarios de Ibáñez, se fueron a Europa y conformaron el comité revolucionario de Paris, que conspiraba y esperaba cualquier oportunidad para hacer caer al caudillo militar.

\footnotetext{
No obstante lo anterior no hay mayores antecedentes que liguen a la sublevación de la armada con Alessandri, pues el, ademảs de asistir a la reunión de notables que citara el vicepresidente Trucco la noche del 1 de septiembre, condenó la rebelión "haciendo ver la conveniencia de que todos los elementos civiles se pusieran al lado del gobierno para evitar la posibilidad de cualquier dictadura. Agrego que no estaba de acuerdo con muchos de los actos del gobierno, pero que en los momentos porque se atravesaba, de graves responsabilidades, era necesario apelar al patriotismo de todos los chilenos y termino manifestando que estaba dispuesto a colaborar decididamente a fin de mantener ia integridad del gobierno"

Tras leer esas frases, uno puede llegar a pensar que solo son palabras de buena crianza, pero en defensa de Arturo Alessandri, hay que mencionar que en el momento en que se produjo el amotinamiento de las tripulaciones, se encontraban ent el gobierno dos fervientes partidarios de este, y nada menos que en las importantes carteras de interier en el caso de Horacio Hevia, y de guerra en manos de Enrique Bravo. Es más, estos secretarios de estado eran constderados les "halcontes" del gobierno, que al enterarse de la sublevación progusieron "dominar el motin y dar un castigo ejemplar a los responsables, funto con prescindir de la negociacion y aplicar "ipso facto" la mano dura. Por este tipo de conductas, que fueron catalogadas de una "intransigencia peligrosa" para los diticiles momentos que vivia el pais, fueroe removidos de sus cargos, propiciando la caida de todo el ministerio. Finalmente, para reafirmar lo anterior, hay que sealar que la supuesta participación de Alessandri tampoco explicaria los levantamientos de Talcahuano, Valparaiso y Quintero.

Sobre la posible participación del general en el motín, se sehalo en ese tiempo que la tebelión obedecia a un movimiento ibañista, dírigido por el almiraate Carlos Frödden. el cual habia sido visto en Coquimbo a fines de agosto de ese affo, Esta Ultima afirmación se basa principalmente en lo experesado por el contralmirante Edgardo Von Schroeders, que sabia de la estrecha amistad entre Fröddern y el gobernador maritimo de Coquimbo, capitan de corbeta retirado Guillermo Valenzueha, llamandole especialmenté la atención que esta autoridad no bubiera comunicado a Santiago sobre el motin de la marineria en la mañana del dia fo de septiembre. cuando debió haber conocido la sinuación, sino lo hizo despues de las 17.00 horas, con posterioridad inctuso al comunicado de los sublevados".

A pesar de lo anterior, es dificil encontrar alguna influencia ibanista en el movimiento, pues por el sólo hecho de que el general Tbánez era un adversario acérrimo tanto de Alessandri como del comunismo, su participación en mstus hechos seria una contradicción, además en el primer punto de las existentes en el petitorio del personal de la base naval de Talcahuano se señalaba lo siguiente: "1" Castigo inmediato y confiscación de todos los bienes de los que llevaron al pais a la bancarrota: Lo que era una dara alusión a lbehez del Campo, 2 su ministro de hacienda Pablo Ramirez y al de marina Carios Frödden. No obstante lo anteriot, no se puede descartar de plano esta hipótesis, pues curiosamente el almirante Frodden se encontraba cerca de Caquimbo durante los incidentes, to que le valió su detención.

2 Donoso, Ricardo. 1954. Alessandri Agitador y Demoledor. México. Fondo de Cultura Economica, Tomo II, p. 27.

Ibid, p. 31
}

Revista de Historia, año 18, vols. 18-19, 2008-2009, pp. 139-152. 


\section{CONTEXTO INTERNACIONAL}

Hay que señalar que "en 1927 el Perú adquirió, primero dos y luego otros dos submarinos excelentes de la clase "R" en los Estados Unidos y como las relaciones con Chile, desgraciadamente no eran cordiales en aquel entonces, este aumento de las fuerzas navales peruanas debía influir en la política naval chilena" 4 Recordemos que el tema de Tacna y Arica sólo se fue a solucionar en forma salomónica en 1929 bajo los gobierno de Carlos Ibáñez del Campo de Chile y Augusto Leguía y Salcedo del Perú.

A continuación veremos que la respuesta naval chilena al avance del país del norte, aparentemente tuvo relación con la posterior sublevación de la marinería, pues las medidas concretas que tomo Chile fueron por una parte la construcción de los seis pequeños destructores antisubmarinos tipo "Serrano"5 y por otra el envío del buque insignia de nuestra escuadra y a la vez el buque más poderoso de sudamérica, el acorazado "Almirante Latorre" a inglaterra para repotenciarlo. Entre otros adelantos que se le hicieron a este último, estuvieron la inclusión de "bulgues" para su protección antisubmarina de los temibles torpedos submarinos peruanos. Esta nave zarpó de chile el 15 de mayo de 1929 y regresó el 5 de marzo de 1931.

\section{PARTICIPACIÓN DE LOS "COMITÉS REVOLUCIONARIOS"}

Una vez hecha esta contextualización política, debemos señalar que durante la estadía de "Latorre" en el puerto de Devonport Inglaterra, el comité revolucionario de Paris se acercó a la unidad y a su tripulación. "enviando un delegado especial que hizo en él activa y decidida campaña"6, según el almirante Edgardo Von Schroeders, fueron estas visitas las que propiciaron el levantamiento de la escuadra y entre otras cosas señala: "La bomba con espoleta de tiempo que se escondió en el Latorre antes de abandonar Inglaterra, estalló el $1^{\circ}$ de septiembre de 1931, en el entrepuente de las tripulaciones, iniciando así el derrumbe del nuevo presidente constitucional señor Montero." 7

El jefe de la policia de investigaciones e incondicional de lbáñez, Ventura Maturana también apoya esta tesis y señala "Una información de muy buena fuente me advirtió que, minada la disciplina de la tripulación por agitadores de Paris, se sublevaría al tocar aguas chilenas bajo el pretexto de que no se había cancelado el importe de las composturas y transformaciones del barco. Salvado a tiempo el motivo, quedo en cubierta el germen de la semilla de desmoralización que había de dar frutos envenenados el $1^{\circ}$ de septiembre de ese año"8.

A pesar de los antecedentes mencionados anteriormente, no hay que perder de vista que el objetivo principal de los "comités revolucionarios" en el extranjero, era lograr la caída de Carlos Ibáñez del Campo, la cual se concretó el 26 de Julio, es decir más de un mes antes de producirse la sublevación de la marinería. Por considerarse a esta hipótesis anacrónica con los acontecimientos, se descarta como "principal" motivación de la insurrección naval.

Sin lugar a dudas el hecho de que políticos hayan interactuado con algunos marinos es un hecho anormal, que merma la moral de estos últimos, pero de ningún modo en este caso fue decisivo. También debemos considerar que si la premisa original del comité revolucionario era que el "Latorre" se sublevara al tocar aguas chilenas, no se cumplió ya que el buque en cuestión había regresado de Inglaterra el 5 de marzo, llevando cerca de 6 meses en territorio nacional hasta el momento en que se produjo la sublevación. Además con una supuesta participación de los comités revolucionarios extranjeros, no se explicarian los levantamientos de Talcahuano, Valparaiso y Quintero, que suelen olvidarse cuando se habla de la sublevación de la armada, centralizándola exclusivamente en Coquimbo.

\footnotetext{
1:Fuenzalida Bade, Rodrigo 1969. La Armada de Chile desde la Alborada al Sesquicentenario (1813.-1968). Armada de Chile, pp. 1.158 y 1.159.

s Ibid, p. 1.159. Estos Destructores Antisubmarinos fueron el: "Serrano", "Orella", "Riquelme", "Hyart? "Videla' y "Aldea".

López Urrutia, Carlos. 1969. Historia de la Marina de Chile, Santiago, Editorial Andrés Bello, p. 357. Segùn el historiador naval Carlos Lopez Urrutia "Estos seis buques fueron tal vex las unidades mas eficientes que ha tenido la Armada de Chile."

- Fuenzalida Bade, Rodrigo, Op Cit., p. 1.174.

Donoso Ricardo, Op. Cit, p. 55.

1. Idem.
} 


\section{PARTICIPACIÓN COMUNISTA}

Como ya señalamos anteriormente además de responsabilizar ailes comités revolucionarios anti Ibáñez del levantamiento, también se culpó a los comunistas de la situación y dentro de los primeros hombres que apoyó esta tesis, estaba el comandante en jefe del ejército de ese periodo, el general Indalicio Téllez Cárcamo, quien llegó a escribir una circular hacia sus dirigidos. Este mensaje lo escribió el general Téllez producto de sus propias convicciones, por su clara animadversión hacia el comunismo, y porque en el período se habló muy fuertemente de una infiltración en la escuadra, por los "rojos" cuyos instrumentos serian algunos cabos despenseros, en especial Manuel Astica Fuentes y Augusto Zagal Anabalon.

Como antecedentes a favor de la participación comunista en la sublevación de la armada, está el hecho de que tres de los líderes de la sublevación tanto en Coquimbo como en Talcahuano, tuvieron tras su desvinculación con la Marina una cercanía con el partido, como fue el SOM (R) Ernesto Gonzáles, quien incluso tuvo una fallida candidatura a diputado por el PC ${ }^{9}$ en la década de los 30 . Por su parte el CB1 (R) Manuel Astica según don Germán Bravo Valdivieso era militante de este partido en $1936^{10}$. En el transcurso de esta investigación se pudo ratificar la cercanía con el partido comunista de este último, a través de conversaciones sostenidas con el ex-senador y ex-secretario general del partido don Luís Corvalán Lepez ${ }^{11}$ y con el escritor y militante comunista Fernando Quilodrán, ${ }^{12}$ quienes lo conocieron personalmente. También el otrora profesor de la escuela de grumetes y líder de la defensa de Talcahuano, don Pedro Pacheco, estuvo ligado al partido, esto se pudo confirmar en las mismas conversaciones con los señores Corvalán y Quilodrán, y en un dialogo con su hija, la señora Ximena Pacheco ${ }^{13}$, quien fuera además la última secretaria personal del destacado escritor, ex-senador y ex-secretario general del partido don Volodia Teilteilboin.

Otros antecedentes lo representan los escritos de Jan Valtin, un renegado comunista en "La Noche Quedo atrás" donde señala que "el motín de la escuadra chilena fue una acción genial de la Sección Marítima de la Tercera Internacional." 14 y también lo señalado por Gonzalo Vial Correa, en el sentido que previo al motín un enviado del sindicato de los astilleros de Coquimbo, fue a Santiago a comunicarse con el lifder comunista Elías Lafferte para informarle de la inminencia del levantamiento de la escuadra en ese puerto ${ }^{15}$.

Finalmente la última vinculación de relativa importancia, entre el partido comunista con la sublevación de la armada, es la coincidencia entre el levantamiento naval chileno con el británico en "Invergordon", de septiembre año 1931; con la de los cruceros peruanos "Grau" y "Bolognesi" en mayo de 1932. Estos movimientos además pueden ser relacionados con las sublevaciones del mítico Acorazado "Potemkin" durante la revolución rusa y de la Flota Imperial Alemana casi al finalizar la I Guerra Mundial.

A pesar de los antecedentes presentados, esta investigación demostrará que la participación comunista no fue ni el detonante de la sublevación, ni menos el factor principal de la misma, pues la información aportada no es concluyente. Si bien es cierto que se pudo constatar que Gonzáles, Astica y Pacheco estuvieron ligados al partido, pero sólo en forma posterior, no en 1931. La relación del SOM (R) Gonzáles con el PC fue más bien circunstancial, por ser este el único partido que trabajó en su defensa cuando iba a ser fusilado, además como se mencionó anteriormente luego estuvo ligado a Alessandri, que terminó su $2^{\circ}$ periodo como un gobernante de derecha.

Del CB1 (R) Astica, se puede decir que si hay un contacto cercano con el comunismo, pero constatado posteriormente a 1931, ya que como menciona Gonzalo Vial, en su juventud además de baber hecho sus estudios básicos y medios en colegios de la iglesia y luego estudiar electrotecnia en la misma Universidad Católica, fue presidente de la "Unión de Centros", institución juvenil de la iglesia que luchaba por la reforma social, pero en la forma de un cristianismo de izquierda, contrario al comunismo, incluso rememora que el año 25 fue con varios estudiantes a la pampa salitrera a formar sindicatos católicos, pero fracasaron. Posteriormente antes de entrar a la armada, pasó por "El Diario Ilustrado", bajo las órdenes de

\footnotetext{
9 Vial Cotrea, Gonzalo. 2001. Historia de Chile, De la Republica Socialista al Frente Popular (1931-1938). Santiaga Editorial 2tg-Zag, Volumen V. p. 77.

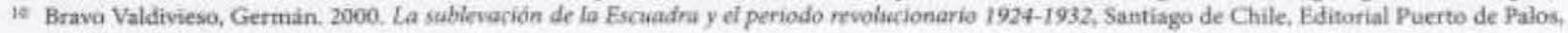
P. 101.

11 Entrevista realizada el Säbado 26 de enero del 2009 , en casa del dirigente, en Santiago

12 Conversación sostenida el Viernes 18 de enero del 2008, en la Sede Central del Parfido Comunista en Santiago.

13 Conversación telefónica sostenida el Viernes 25 de enero del 2008

14 Bravo Valdivieso, Germán. 2000, La sublevación..., p. 99. Citado de la "Sublevación de las Tripulaciones de la Escuadra" septiembre de 1931. Trabajo para la Cátedra de Historia de Chile IV. Intituto de Historia, Universidad Católica de Valparaiso. Profesor Baldomero Estrads Turra. Alurno 1 Mauricio Corvalán Constantino, ayudante Ximena Recio Palma. Viña del Mar, diciembre de 1986.

is Vial Correa, Gonzalo, Op Cit,p. 74
}

Revista de Historia, año 18, vols. 18-19, 2008-2009, pp. 139-152. 
Rafacl Luís Gumucio, de quien era admirador y luego por "El Día" y "La Mañana de Talca", todos diarios católicos $^{16}$. Este pasado cercano a la iglesia lo sacó a relucir en su defensa, cuando se encontraba preso tras el fracaso del movimiento, mencionando que él había luchado desde hace diez años, contra el comunismo en las aulas 17

Sobre el CB1 (R) Zagal, los escasos antecedentes que existen se encuentran en la defensa que realiz 6 su abogado ante el tribunal, en el juicio por su participación en la sublevación. Este en algunos momentos llegó a decir: "Yo invóco los nobles sentimientos de los miembros de este Tribunal y dirigiéndome a sus corazones voy a hacer valer como atenuante, la circunstancia de que Zagal es un niño recién ingresado al Servicio de Contabilidad en el Latorre, incapaz, por lo tanto, de poseer toda esa inmensa entereza de carácter que habría necesitado para oponerse a las resoluciones de todas las tripulaciones. Es además un joven de conducta invariablemente intachable desde su niñez. Pertenece a una familia honorable. Tiene tres hermanos presentes en esta audiencia, profesionales los tres, que durante aquellos lamentables sucesos, mientras Zagal estaba en el Latorre, ellos desfilaban como reservistas del Tacna bajo la bandera de la Patria, ofreciendo sus vidas incondicionalmente a la Republica en peligro". Cuando Zagal se levantó del banquillo para retirarse de la sala, las lágrimas asomaban a los ojos de muchos de los asistentes."18

Si se omiten los comentarios sobre la persona del marino, propios de una defensa a un hombre que corre el riesgo de ser fusilado y se pone atención a los antecedentes familiares, una familia profesional y además reservistas del ejército que se opusieron activa y decididamente al movimiento insurrecto, tal vez no nos entregará información sobre el comportamiento de Augusto Zagal al interior del "Latorre", ni de su nivel de compromiso con el partido comunista, pero es un atenuante para creer que esta relación fue circunstancial. Junto a esto, no hay datos que liguen directamente al marino con el PC, ni antes ni después de 1931.

Sobre Manuel Astica y Augusto Zagal, los cabos despenseros, el historiador Ricardo Donoso y el mismo almirante Von Schroeders se planteaban las siguientes interrogantes ¿ Por qué dos personas con estudios superiores o con familias de profesionales se contrataron por la armada en el modesto cargo de cabos despenseros, ayudantes de contador?, también ¿Por qué se instaló una impresora a bordo đel Latorre justo en ese período a la llegada desde Inglaterra?; ¿Por qué los Cabos despenseros se contrataron "curiosamente" apenas un par de meses antes de la sublevación? y ¿Por qué estos marinos nuevos tuvieron tanta participación en la sublevación? ${ }^{19}$.

El por qué dos personas con tanta educación para la época, postularon a un cargo tan modesto, lo explica muy bien Gonzalo Vial: "No eran lo que su nombre pareciera indicar, sino auxiliares de un nuevo sistema contable, el "Central Store" británico, que la Armada deseaba introducir. Hubo al efecto un concurso. cuatrocientos postulantes, y once seleccionados, entre ellos Astica, que ocupo el primer lugar (aseguraba), y también Zagal. Los elegidos deberian seguir durante seis meses un adiestramiento en el Latorre-a cargo de un oficial especialista- y luego se les dispensaría por las diversas reparticiones navales, diseminando asi el sistema. De allí la presencia de los dos lideres en el acorazado. Además, respecto de Astica, quizás operaba-y sus recuerdos lo insinúan-un "sueño de juventud". que aunara la lectura de Loti, Salgari, Julio Verne y nuestro D Halmar. "viajar por todos los mares del mundo". "20 También hay que considerar que la gente de mar en la armada ingresaba generalmente como grumetes, y estos lo hicieron como cabos $1^{\circ}$, varios grados por sobre el común de los marinos.

La explicación de la existencia de una impresora al interior del "Latorre", es comprensible al dimensionar la magnitud del buque, pues este poseía un desplazamiento aprox. de 28.000 toneladas, una eslora (largo) de 625 pies (190,5 mts.), una manga (ancho) de 92,5 pies ( 28,2 mts.), un calado medio (bajo línea de flotación) de 28 pies ( 8,5 mts.) y una tripulación de 1.075 hombres, 21 por lo que para transmitir brdenes, enviar circulares, etc. en forma escrita cra necesaria una imprenta.

Para hacerse una idea de la magnitud del buque, es válido el testimonio del SOF (R) Manuel Chamorro Moreno, quien además de ser un investigador naval y publicar numerosos artículos en diversos diarios de circulación nacional, prestó servicios por varios años en el "Almirante Latorre", y en una conversación que se sostuvo con él, mencionó que muchas veces no alcanzaban ni siquiera a llegar al baño,

\footnotetext{
16. Vial Correa, Gonzalo, Op. Cit. pp. 39-40.

17. Extraido dei diario La Patria del Viernes 18 de sepriembre de $1931, \mathrm{p}, 8$.

is lbid.

19 Donoso Ricardo, Op. Cit, p. 55.

20 Vial Cotrea, Gonzalo, Op. Cit., p. 41.

21 Fuenzalida Bade, Rodrigo, Op. Cit, p. 1.112.
} 
porque el buque era muy grande, motivo por el cual se dispuso la colocación de "tachos" metálicos en diversos sectores de la nave, para que el personal pudiera hacer sus necesidades en caso "de emergencia". 22

La explicación al por qué los cabos despenseros se contrataron sólo dos meses de la sublevación puede ser obvia, pero hay que responderla, y es porque precisamente en ese periodo comenzó la contratación de personal externo con estudios superiores al común de la época, para aplicar en la armada el modelo británico del "Central Store", lo que no se había realizado antes, y a través de un concurso ingresaron Astica Fuentes y Zagal Anabalón.

El por qué estos cabos recientemente contratados tuvieron tanta participación en el levantamiento de la marineria, hay que entenderlo necesariamente en que se ganaron rápidamente el respeto y la consideración del resto del personal de gente de mar, y no se explica por una infiltración comunista, pues entonces cabe preguntarse ¿Que hubiese pasado si los sargentos no los hubiesen invitado a participar en el movimiento a través de la redacción del petitorio?, lo más probable es que el levantamiento se hubiese producido igual, tal vez con otro cariz, pero no habría variado mucho, ya que en todo momento, por lo menos en el "Latorre" el comandante en jefe de la flota sublevada, era el suboficial más antiguo, el SOM Gonzáles, conservándose al menos en ese aspecto la jerarquía castrense, así que, en caso de que no hubiesen sido invitados a participar, ellos como cabos $1^{\circ}$ no hubieran podido hacer mucho, ya que no contaban con el poder efectivo para liderar por su cuenta una sublevación de ese tipo.

Con respecto a don Pedro Pacheco, su relación con el comunismo como ya se señaló es también cercana, pero no esta comprobado que él hubiera sido simpatizante siquiera de esa ideología en los tiempos cuando hacia clases en la escuela de grumetes, los días de la sublevación.

En ese entonces al parecer con demasiada liviandad se tildába a alguien de comunista, pues durante el mismo juicio a Pacheco uno de los testigos acusadores, el guardiamarina Brañas, afirmaba que el profesor tenía varios libros de esa tendencia en su poder. Ante esto el señor abogado del preceptor don Tomás Mora. pide la palabra y expresa:

"-Señor presidente: Que diga el testigo que libros de autores comunistas conoce como de propiedad del profesor Pacheco" 23 . Al ser interrogado, el oficial (algo desinformado políticamente) señal6:

"- Le conozco varios señor presidente, entre otros algunos de Mahatma Gandhi.

Ante la declaración del testigo, se produjo un momento de silencio en la sala y se cruzaron significativas miradas, pues como es sabido, el Mahatma Gandhi es un reputado y conocido oriental, sumamente conocido por sus recientes campañas nacionalistas pasivas de la India." 24

Además de esto, hay que tener presente que el levantamiento de la marinería comenzó el día martes 1 de septiembre en Coquimbo y sólo el jueves 3, la base naval de Talcahuano sumó su adhesión a los camaradas del norte, por lo que sería anacrónico culpar al profesor Pacheco o a los posibles simpatizantes comunistas de dicho puerto, como los grandes responsables de la sublevación de la marinería.

En relación a lo señalado por Jan Valtin, de que "el motín de la escuadra chilena fue una acción genial de la Sección Marítima de la Tercera Internacional." no puede ser confirmado por otros antecedentes. quedando sólo en el ámbito de las especulaciones. Según don Luís Corvalán, quien fuera simpatizante en 1931 del partido, e ingresara a militar en él en febrero de 1932, al preguntársele por Jan Valtin, sef̂aló que primera vez que escucha de él y que esas hipótesis sobre participación de la Komintern, "son puras leseras", pues el PC no tenia tanta influencia en ese tiempo. También mencionó que el partido si apoyó posteriormente al movimiento naval, pero que no lo provocó, agregando que en caso de haber originado la sublevación, a pesar del fracaso que tendría posteriormente, hubiese sido un motivo de orgullo para el PC y no habría motivo para ocultarlo 25 .

\footnotetext{
a2 Conversación sostenida el miércoles 23 de enero del 2008, en el Departamento de Relaciones Publicas de la Armada, en el Edificio de Las Fuerzas Armadas; donde et SOF Chamorro (R) se desempenia.

13. Fxtraido del Diario El Sur, domingo 27 de septiembre de 1931, p. 10.

24 ibili.

25 Entrevista realizada el Sábado 26 de enero del 2008, en casa del dirigente, en Santiago. Vial Correa, Gonzalo, 2001. Historia de Chile. De la Repubíca..., p. 77

A esto hay que sumar que el Buro Latinoamericano criticaria al partido comunista chileno por su "debilidad orgánica", reflejada en su "escasa. raigambre en el proletariado de las grandes industrias" y faita de trabajo politico respecto a soldados y marineros. Ibid, p. 76.

Por su parte, tanto el aimirante Von Schroeders como el suboficial mayor Gonzales, hablan de una discrepancia entre "el pancismo" versus "revolucion", representado lo primeto por los rebeldes navales que velaban por sus reivindicaciones, contra la revolución que planteaban los comunistas, pero sülo en un segundo momento ya que el Comité Central del PC se vio sorprendido por el comienzo de la sublevación.
}

Revista de Historia, año 18, vols. 18-19, 2008-2009, pp. 139-152. 
Al referirse a este punto Luís Vitale señala: "El levantamiento tuvo al comienzo un carácter economicista: impedir la rebaja de sueldos. Pero a medida que se agudizaba el enfrentamiento, las demandas adquirieron un tono político. Los marineros empezaron a confratemizar con los obreros. Sin embargo, el comando de la rebelión no pudo o no quiso concretar ningún acuerdo con las organizaciones obreras más importantes, como la FOCH y la YWW"26.

Sobre el enviado del sindicato de los astilleros de Coquimbo, para advertirle en forma urgente a Elfas Lafferte del levantamiento de la escuadra, Corvalán señaló que podía explicarse por el contacto de algún obrero con algunos marinos de la escuadra 27, recordemos que el "Almirante Latorre" junto a la flota de instrucción, se encontraba hacía tiempo anclado en el puerto de Coquimbo.

En relación a la simultaneidad de los movimientos navales chilenos y británicos, esto es cierto, ya que ambos se produjeron en septiembre de 1931. pero antecedentes que los ligaran en forma concreta no existen, quedando sólo en el terreno de las especulaciones, como el hecho de que Devenport, (lugar donde se encontraba el Latorre en su repotenciamiento en Inglaterra) fuera un activo centro propagandístico del $\mathrm{PC} 28$. Esta hipótesis sin embargo se estaria contradiciendo con la que plantea la posible infiltración comunista por parte de los cabos despenseros Astica y Zagal, ya que ellos ingresaron a la armada sólo en junio de 1931 , meses después de la llegada del acorazado a aguas chilenas.

Luego, sobre la posible relación de lo acontecido en Chile con la revuelta de buques peruanos, se debe mencionar que esta última está más relacionada al APRA que al partido comunista, que precisamente es su adversario en Peru.

Más lejos en el tiempo, es indudable reconocer la participación comunista en los movimientos navales rusos y alemanes, pero esto no basta para unirlos a la sublevación de la marinería en Chile del año 1931, ni tampoco para conformar un "modus operandi" de rebeliones navales como política del partido, pues estas últimas se dieron en momentos coyunturales y propios de esos países.

De este modo se demuestra que la participación comunista no fue fundamental para producir el levantamiento naval, a lo que hay que agregar que dentro de las proclamas radiales, en reiteradas ocasiones señalaron que no estaban influenciados por ninguna ideología, ni comunista, ni anarquista. Además uno de los sublevados más renombrados del periodo el suboficial, Guillermo Steembeker, más conocido por su apodo de "comodoro", pertenecía a grupos nacionalistas ajenos completamente al comunismo, llegando a ser secretario de una "Liga Patriótica" en Talcahuano.

Finalmente hay que recordar que no basta con tener infiltrados comunistas, o gente con tendencia izquierdista o que propicie reformas sociales en las filas, para levantar a las fuerzas, pues en agosto del año 1973 "un grupo de suboficiales de la Marina, encabezados por el sargento segundo Juan Cárdenas, y entre los que se contaba a los cabos segundos Teodosio Cifuentes y Antonio Ruiz, llegaron a Santiago a entrevistarse con el senador socialista Carlos Altamirano, con el diputado del MAPU Oscar Guillermo Garretón, y con el dirigente del MIR Miguel Enríquez" 29 , y esto al ser controlado, no desembocó en una sublevación por parte de la armada. 30

\section{SITUACIÓN ECONÓMICA}

Para entender el problema económico que vivía el país en ese entonces y que de una u otra forma estuvo ligado al amotinamiento, debemos necesariamente volver al gobierno del general Carlos Ibáñez del Campo, y mencionar que visto en perspectiva (nadie se esperaba una crisis internacional, como el "Crack" que se produjo con la caída de la Bolsa de Nueva York el jueves negro del 24 de octubre de 1929) realizó un excesivo gasto interno, orientado principalmente a las obras públicas, a reformar el aparato del estado y a crear

3. Vitale, Luis - 1994. Interpretación Marxista de la Historia de Chile, de la Republica Parlamentaria a la Republica Socialista. De la Dependencia inglesa a la norteamericana (1891-1932), Santiago, Ediciones LOM, Tomo V, p. 322

I7. Entrevista realizada el Sabado 26 de enero del 2008, en casa del dirigente, en Santiago

28. Vial Correa, Gonzalo Op, Cit, p. 75

19 Totoro Taulis, Dauna 1999, La Cofradía Elindada, Chile Civil y Chile Militar Traama y Conflicto, Santiago de Chile, Editorial Planeta, 2* Edición, p. 190 .

30 Además como dato anecúótico se puede mencionar que tanto Saivador Allende, como Victor fara y el padre Alberto Hurtado, pasaron por las filas del ejército cumpliendo con su servicio militar. El fallecido Fx-Presidente de la Republica Salvador Allende Gossens, cumplio con su Servicio Mijtar los anos 1924-25 en el Ejercito, dentro del arma de Caballeria en los Regimientos "Coraceros" con asiento en Vina del Mar y el "Lanceros" con asiento en Tacna (en ese entonces se encontraba ocupada por Chile). El cantautor Victor Jara cumpltó con su Servicio Militar en la "Fseuela de Infanteria" de San Bernardo el afo 1951. E Sacerdote Alberto Hurtado Cruchaga cumplí con su Servicio Militar en el Regimiento de Infanteria "Yungay" el año 1920. 
nuevas instituciones. A su vez se produjo un gran endeudamiento exterior, principalmente en los EE. UU. el mismo país que comenzó la crisis y por supuesto que una vez desatada esta, dejo de enviar préstamos, con graves repercusiones para el país.

Otro factor que afectó gravemente a la nación, fue un mal manejo comercial de la naciente COSACH, ya que se generó una "sobreproducción de salitre ordenada por el Presidente Ibáñez y su Ministro Pablo Ramírez, salitre que no tuvo mercado a pesar de hallarse en Europa en bodegas a consignación", 31

Por su parte, en el pafs "los chilenos minimizaban el impacto de los factores externos, y maximizaban la responsabilidad del "tirano", por los errores económicos que se le atribuían." 32 Pero sucedió que Ibáñez dejó el mando el 26 de julio de 1931 para evitar una guerra civil, ${ }^{33}$ y a pesar de ello la crisis continuo.

Una vez alejado del poder el general, el mando de la nación paso al presidente del senado, don Pedro Opaso Letelier con el titulo de vicepresidente, este cargo lo utilizo por un día, para evitar susceptibilidades de que pudiera representar la continuación del régimen del militar, ya que a ese parlamento que presidía, conocido como "congreso termal" se le acusó de ser designado por Ibáñez y por ende earecer de representatividad nacional. De este modo a la siguiente jornada entregaba a su vez el poder a don Juan Esteban Montero ${ }^{34}$. Él y su ministro de hacienda Pedro Blanquier tuvieron la difícil misión de volver las cosas al orden y sacar al país del caos financiero. El 20 de agosto Montero entregaba el puesto a su ministro del interior don Manuel Trucco, para postularse a la presidencia de la república y ser electo a través del sufragio.

Mientras tanto, dentro de las medidas económicas que iba a tomar el secretario de estado de hacienda, se encontraban las temidas rebajas a los salarios de los empleados fiscales, lo que incluía a las fuerzas armadas, esto se hizo saber el 27 de agosto de 1931. "Al día siguiente cl 28, un comunicado del Gobierno precisó la forma como operaria la rebaja: $12 \%$ sobre las remuneraciones mensuales que no excedieran de 250 pesos, y $30 \%$ sobre las superiores a esta cifra. Era un "préstamo" de los funcionarios públicos al Estado, el cual lo devolvería cuando pudiera y si pudiera.

Con posterioridad, se aclaró haber existido un error en el comunicado. Hasta 250 pesos mensuales, no habrá descuento alguno; en el exceso, se aplicaría una tabla creciente: mínimo, $12 \% ;$ máximo, $30 \%, 35$

\section{MOTIVACIÓN ECONÓMICA}

Para el historiador Gonzalo Vial Correa esta rebaja de sueldos es la detonante de la sublevación y los otros elementos son solamente incidentales o posteriores a la explosión de la misma ${ }^{36}$. A esto hay que agregar que "El sueldo de los suboficiales, cabos y sargentos era para empezar exiguo". 37 Con todo esto nos podemos hacer una idea que nos ayudará a entender la motivación del levantamiento.

Dentro de los principales puntos de la "Proclama" que fue la comunicación al ministro de marina del "Estado Mayor de las Tripulaciones" localizado en el "Latorre" el martes I de septiembre de 1931: señalan cosas como:

1. Que es un deber de patriotismo obliga a las tripulaciones de la Armada a no aceptar dilapidaciones ni depredaciones de la hacienda del pais, por la incapacidad imperante del gobiemo actual y la falta de honradez de los anteriores.

2. Que los actuales gobernantes, para solucionar la situación económica, solo han recurrido a la misma política de sus antecesores, con una falta absoluta de iniciativa y de comprensión, por lo tanto acuerda:

$1^{\circ} \quad$ No aceptar, por ninguna causa, que los elementos modestos que resguardan la administración

\footnotetext{
31. Guzmán Cortes, Leonando, 1966. Un Episodio Glvidado de la Historia Nacional (fulio-Noviembre 1931), Santiago Editorial Andres Belio, p. 16.

12. Vial Correa, Gonzalo, Op, Crs, p. 34.

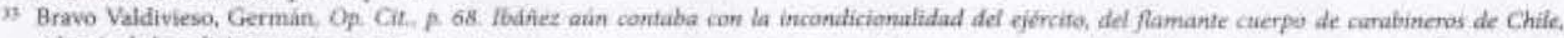
adendis de la policia investigaciones.

3 Vial Correa, Gonzales, Op. Cit, p. 34

is Ibid, p. 37.

* Ibid. p. 38 .

Bravo Rios, Leonidas, Lo que supo un auditor de Guerra, Editorial del Pacifica. Santiago, 1955, p. 30.

De igual pensamiento ex quien fuera auditor general del ejército don Leonidas Bravo Rios y padre det historiador Germàn Bravo Vaidivieso, pues. sentala como ejemplo que: "Al soldado chileno puede exigirsele un trabajo sin descanso, puede enviarsele de frente al sacrificio y a la muerte, puede tenersele sin ropa, sin armas, sin elementos de trabajo, puede iticluso, obligarsele a el, personalmente, a que soporte el hambre y el frio, pero-1odas esas virtudes de abnegación y sacrificto desaparecen cuando el soldado sabe que son su mujer y sus hijos les que pasan harnbre.

El hambre que el soldado acepta para si, no lo acepta para los sayos. y si llega el momento de la prueba. desaparece la disciplina y se pierde la más grande de las virtudes de nuestro soldado-

3 López Urrutia, Carlos, Op. CH, p. 361.
}

Revista de Historia, añด 18, vols. 18-19, 2008-2009, pp. 139-152. 
y paz del pais, sufran cercenamiento y cl sacrificio de su escaso bienestar para equilibrar situaciones creadas por malos gobernantes y cubrir deficits producidos por los constantes errores y falta de probidad de las clases gobernantes. 38

Lo expresado anteriormente nos señala claramente el rechazo de los marinos a la rebaja de los salarios y la importancia del factor económico en la sublevación, pero no es concluyente, pues debería considerarse dicha reducción de sueldos como la "chispa" que hizo explosar el polvorin, similar al asesinato del archiduque Francisco Fernando que desencadenó la I Guerra Mundial, pero no como el factor de fondo, pues no basta con una baja en las remuneraciones para sublevar a las fuerzas armadas, ni en especial para levantar al personal de suboficiales, pues en el pasado se habian encontrado en peores situaciones, como señala Bravo Valdivieso "Los sueldos que gozaban las fuerzas armadas eran miserables y no se vislumbraba ningún camino de solución..... Los suboficiales completaron en 1924 seis meses impagos". 39

\section{PARTICIPACIÓN DE LOS OFICIALES}

Existen diversas versiones que hablan sobre participación de la oficialidad naval en la insurrección, por ejemplo el marinero Luís Pérez, uno de los condenados a muerte en el posterior juicio señaló: "los tripulantes tenían el respaldo de la casi totalidad de los oficiales de la escuadra, quienes los habrian alentado a seguir adelante con su accionar $\mathrm{e}$ incluso les habrian ofrecido ayuda técnica, lo cual ellos habrian rechazado". 40

Quien más confirma la participación de los oficiales en la sublevación, fue el marinero José M. Cerda, integrante del escuadra del sur, que zarpó de Talcahuano a Coquimbo el jueves 3 de septiembre de 1931 y que señaló: "los oficiales procuraron desde un principio jugar a dos cartas....Si ellos hubiesen sido contrarios al movimiento, no habrían entregado los buques de mutuo propio, sin presión alguna de parte de las tripulaciones, $y$ aún más, algunos -exhortaron a sus subaltemos, a que se plegaran a é." 41

Uno de los testimonios más interesantes referente al tema, es el del $\mathrm{SOM}^{42}$ Gonzáles, quien al enterarse de que había sido condenado a muerte por la corte marcial, le pidió a una hermana suya liamada Berta, que fuera a buscar al "Latorre", unos documentos que comprometían a algunos oficiales, una especie de última medida desesperada para intentar revertir su fallo y salvarse del pelotón de fusilamiento. Entre los oficiales implicados con las nuevas evidencias, se encontraba el capitán Roberto Valle, este según Bravo Valdivieso había entregado al "comodoro" Hozven una pistola, la cual "curiosamente" falló tres veces, cuando el jefe quiso oponerse por la fuerza a la sublevación, y además la noche previa a esta, "sospechosamente" habia pedido su pistola de servicio al guardiamarina Barros, que precisamente era el oficial a quien le correspondió realizar la guardia desde las 00:00 a las 04:00 hrs. de aquel martes 1 de septiembre en el acorazado "Almirante Latorre", cuando se produjo el levantamicnto.

Dentro de la información que trajo la hermana de Gonzalles se encontraba una carta de puño y letra del capitán Valle, que señalaba: "estoy seguro que el gobiemo no sabe que también muchos oficiales piensan como ustedes y están en todo con ustedes. 43

No obstante lo anterior, la participación del capitán de corbeta Roberto Valle en la sublevación no está claro, pues el consejo de guerra de las Salinas lo condenó, pero posteriormente la corte marcial en Valparaíso lo dejó absuelto. Dentro de las cosas que se señalaron sobre él, fue que cuando comenzó el bombardeo a la escuadra por parte de la naciente fuerza aérea, él como oficial artillero, se ofrecio a dirigir los

\footnotetext{
34 Bravo Valdivieso, Germán. 2000. La sublevación de la Escuadna y el periodo revolucioniarie 1924-1932, Santiago de Chile, Editorial Puerto de Pa los, $3 *$ Edición, pp. 120-122. Cirado de Von Schroeders. Aimirante Edgando, 1933. El Delegado del Gobierno y el Motin de la Escuadra, Santiago, Imprenta Universo.

3 Bravo Valdivieso, Germain, Op Cat, p. 213

4i) Jbid. P. 213 .

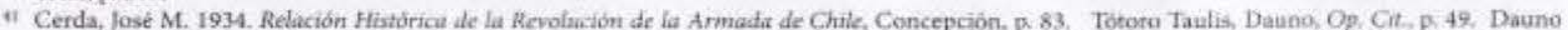
Tótoro sobre el mismo hecho señala que el motin de la armada en septiembre del 31 fue llevado a cabo por oficiales y suboficiales de tendencias de izquierda.

Vial Correa, Gonzalo, Op. Cit. p. 73. Gonzalo Vial mencions al respecto: "No obstante, bubo siempre una veta de simpatia, en los superioses, hacia las peticiones de los alzados, espectalmente hacia la que visaba la rebajz de sueidos.

Por otra parte, tampocir cabe excluir-y hay indicios al respecto-que los oficiales experimentaron ciento orgullo, llamémosto profesional, por dos bechos objetivos de la sublevación

1. La pericia técnica que demostraron los rebeldes manejando las flotas y

2. Su energía y eficacia para rechazar los ataques aetreos:

42 SOM Es la abreviación Suboficial Mayor,

4) Bravo Valdivieso, Germin. Op. Cit, $p, 21$ ?
} 
fuegos antíaéreos del buque, siendo rechazado por los suboficiales ${ }^{44}$. Esto nos dice dos cosas, por una parte como es lógico en caso de bombardeo el buque podría haber sido tocado o hundido, lo que al concretarse cualquiera de las dos opciones, él hubiese podido convertirse en una baja sin posibilidades de defenderse, por lo que esa petición puede ser entendida dentro del contexto de querer sal var su vida, y lo segundo es que con la respuesta de los marinos de rechazar su participación, se demostraría que él se encontraba en una situación de desventaja con respecto a ellos, por lo que la carta "de puño y letra" del capitán Valle, en apoyo a las tripulaciones, bien pudo producirse bajo presión, lo que le restaría toda validez. Aunque eso no se puede comprobar a cabalidad.

Otros antecedentes nos señalan la posibilidad de que los oficiales de la armada o a lo menos algunos de ellos hayan participado o estuvieron de acuerdo con el levantamiento de sus hombres, pues la reducción de salarios los afectaba a todos por igual.

A pesar de lo anteriormente expuesto, en esta investigación no se podría afirmar tajantemente que hubo participación intelectual, ni efectiva de oficiales de la Armada en la sublevación, pero no hay dudas de que estos no se apegaron al reglamento al no ser lo suficientemente enérgicos para reprimir el motín en sus orígenes, pues el código de justicia militar es bastante claro al respecto, ya que como señala en su Art. 269 : "El militar que no empleare todos los medios que estuviesen a su alcance para contener la rebelión o sublevación en las fuerzas de su mando, será castigado con la pena de reclusión menor en cualquiera; si fuere Oficial, además y en todo caso, con la pena de destitución". 45

El no emplear "Todos los medios disponibles" se dio especialmente en las bases navales de $\mathrm{T}$ alcahuano, Valparaíso y Quintero, pues estas se plegaron al movimiento de Coquimbo a los días después, y los oficiales tuvieron tiempo suficiente para prever las posibles eventualidades y tomar las medidas correspondientes. Para confirmar lo acontecido al comienzo de la sublevación del Apostadero Naval de Talcahuano, está el testimonio del marino José M. Cerda que señala. "Además, salvo a los oficiales del "Araucano," no se les presionó en ningún buque ni reparticiones maritimas del puerto" 46 .

\section{SITUACIÓN DE LOS SUBOFICIALES}

Allá por los años 1924-25, los mismos en que se produjeron las intervenciones militares que obligaron al presidente Alessandri a salir del pás y posteriormente a volver, en los suboficiales del ejército ya se notaban signos de molestia, como lo señala Gonzalo Vial: "La indisciplina se manifestaba dentro de los cuarteles en "memoriales" que circulaban clandestinamente entre la tropa exponiendo sus reclamos y reivindicaciones, especialmente en materias que tenían relación con la ley de retiros." En ese mismo periodo un grupo de prominentes patriarcas del partido conservador buscó a los suboficiales. Y esto no era ilógico: si los generales habian dado o aprovechado el golpe de septiembre, y los mayores, capitanes y tenientes el contragolpe de enero... ¿Por que no había de sonar la hora de los suboficiales? ${ }^{4} 7$

Por su parte el suboficial mayor de la armada Ernesto Gonzáles Brion, quien fuera el líder nominal del levantamiento de Coquimbo, que luego incluyó a Talcahuano. Valparaíso y Quintero bajo su tutela, refiriéndose al mismo periodo menciona: "Cuando lo oficiales del ejército y los de la marina derrocaron al gobierno en 1924, las tripulaciones ni siquiera fueron consultadas", y agregó: "Esta actitud de los oficiales destruyó el principio de nuestra carta fundamental que prohibe la deliberación de las fuerzas armadas y lo que es más importante aún, despertó en las tripulaciones el deseo de intervenir directamente en su suerte". Estas, muy lógicamente, se dijeron: Si nosotros somos la fuerza de que disponen a su antojo los oficiales para pedir lo que les beneficie particularmente, ¿Por qué no intentamos por nuestra cuenta corregir lo que nos afecta desfavorablemente, tanto en materia de sueldos, como en la ley de retiro, etc. y nos desentendemos de ellos, asi como lo han hecho siempre con nosotros? Así principio a germinar el espiritu de rebelión.

4. Ibial p. 213

45 1976. Código de Justicia Malitar, Santiago, Fditorial Juridica de Chile, Novena Fdieión, p. 91.

46 Cerda. Jose M. 1934, Relacion Historica.... p. 83.

4. Bravo Valdivieso, Germán. 2000. La sublewacien de la Eschadra.... p. 43. Citado de Vial Correa, Gonzalo. 1996. Historia de Chíe, Alessandri y los Golpes Militurna", Santiago, Editorial Santillana del Pacifico S. A., Yolumen IIL.

Revisfa de Historia, año 18, vols, 18-19, 2008-2009, pp. 139-152. 


\section{MOVIMIENTO "DE CLASE"}

A favor de dicha teoría, está el hecho de que salvo participaciones comprobadas de forma indirecta o circunstancial, casi no existió intervención de los oficiales en el movimiento.

Sobre el planteamiento de un movimiento conjunto entre suboficiales del ejército y de la marina, hay varias prueba concretas, como fue el caso de los suboficiales del regimiento de infanteria $\mathrm{N}^{\circ} 2$ "Maipo", con asiento en Valparaíso, que apoyaron a sus camaradas navales "... el día 5 de septiembre, el General Agustín Moreno, en Valparafso, fue informado de que el cabo músico Alejandro Carrasco Ramírez estaba haciendo correr y firmar un pliego y tarjetas individuales de adhesión a los marineros del "Latorre" ${ }^{+\cdots 4}$.....(nota al pie de pagina): "Este individuo empezó su actividad en la mañana del 2 de septiembre, ocultamente primero, desembozadamente desde que supo que Quintero y Talcahuano se habian alzado también" 49 . La tarjeta que firmaron los suboficiales y algunos soldados era del siguiente tenor "Al comité a bordo del "Latorre", Coquimbo. Suboficiales y tropa regimiento "Maipo", estarán con ustedes en todo momento." 50 Además de dicho regimiento, en la quinta región se adhirieron a los marinos la Escuela de Comunicaciones y la Base Aeronaval de Quintero. 51

Junto al apoyo del R. I. No 2 "Maipo", también dio su adhesión a la insurrección un conjunto de suboficiales, clases y tropas, pertenecientes al II Grupo de Artillerí, del Regimiento de Artillería 52 "Arica" que tenia por guarnición a la Serena y a carabineros de Coquimbo ${ }^{53 *}$

Al revisarse las peticiones como el "Derecho de asociación de las fuerzas armadas en general" 54 , realizada desde Talcahuano o pedir la derogación de ciertos decretos para dejar efectivo el antiguo que fijaba la tabla de sueldos a base del retiro a los 20 años de servicios y voluntario a los 15 años ${ }^{55}$, originada en Coquimbo, se puede llegar a decir que el movimiento buscaba sólo mejorar su situación postrada.

Para entender la animadversión contra los oficiales, están como ejemplos las palabras del suboficial mayor Ernesto Gonzáles Brion, líder de la sublevación, que mencionó: "El Oficial seguía como en los tiempos de la Colonia, tratando al marinero como un sirviente, sin preocuparse de su vida personal, dedicado a instruirlo pero no a educarlo. Esa falta de contactos e interés para sus subordinados, les habría impedido a los oficiales, percatarse del volcán que ardía a sus pies." 56 Él culpabiliza a la Escuela Naval de la mala y clasista formación de sus alumnos, que al egresar "creían saberlo todo" y se refiere a la "regalada vida" que llevaban a bordo, "la que se regulaba por una ordenanza de 1780, dictada para el Ejército cuando la marinería era analfabeta." 57

\section{LA MORAL MILITAR COMO FACTOR DE FONDO}

Los argumentos esgrimidos por la historiografía clásica para explicar el origen de la sublevación de la marinería en septiembre de 1931 no son suficientes, pues si bien es cierto, se puede aceptar que este movimiento sea considerado "de Clase", por la casi insignificante participación comprobada de los oficiales, pero no hay antecedentes suficientes para afirmar que se trataba de un movimiento concertado previamente por suboficiales del ejército y de la armada, pues salvo ciertos grupos de suboficiales de las unidades mencionadas el R. I. N² "Maipo" y el R. A. No 2 "Arica," no paso a mayores en el ámbito militar, es más, estas adhesiones fueron posteriores al $1^{\circ}$ de septiembre, fecha en que comienza la sublevación y además fue precisamente el mismo ejército el que sofocó la rebelión en Valparaíso, Quintero y Talcahuano, llegándose en este último puerto a un cruento enfrentamiento armado con los marinos sublevados.

Por otra parte, decir que el movimiento surgió para buscar una solución a su situación postrada, es exagerado, ya que esta situación se venía arrastrando por bastante tiempo, e incluso tras el movimiento y por

4. Guzmain Cortés, Leconardo, Op. Cit, p. 95.

w) Thid.

so Bravo Valdivieso, Germin, Op. Cit, p. 203

3) Gurmin Cortés, Leotaando, Op. Cit, p. 99.

32 Estado Mayor General del Ejéreito, Historia del Ejército de Chile, Colección Biblioteca del Oficial. Tomo VHI. Pág. 328. El Comando del Regimiento "Arica" y el 1 Grupo de Artilleria tenian por guarnición la ciudad de Antofagasta.

5) Bravo Valdivieso, Germin, Op. Cig. p. 125. Citado de Emesto Gonzales Brion. 1932. "EI Parto de los Montes o La Sublewación de la Marineria". Santiago, talleres Gráficos Cóndor.

94. Tbid, p. 137 .

55 Ibid. p. 126

if Mid, p. 104 .

3) Joid. 
bastantes décadas posteriores, salvo leves diferencias, la situación se mantuvo. Junto a esto, en los petitorios se incluyeron varias demandas y propuestas bastante alejadas del ámbito naval, como fue, el darle pautas al gobierno sobre como pagar la deuda externa, subdividir las tierras, bajar las tasas de intereses en los bancos 58 o pedir la socialización de las industrias 59 .

Del mismo modo, tampoco es motivo de sublevación, las diferencias que existen entre un uniformado del escalafón de oficiales con el de suboficiales, pues esto siempre ha existido y previamente nunca se habia sublevado todo un regimiento o toda la flota por estos motivos. Dentro de estos contrastes esta que los oficiales y suboficiales van a escuelas matrices distintas, también el hecho de que los oficiales además de poseer un status económico, social y cultural superior, se les "rinde honores militares" y que inclusive la convención de Ginebra, creada para regular los conflictos bélicos, enfatiza esta distinción, prohibiendo que los prisioneros de guerra de la jerarquía de oficial realicen trabajos manuales 60 .

Si entendemos que ninguno de los elementos previamente señalados fue capáz por si sólo producir la sublevación, podremos señalar que los planteamientos realizados en este sentido por estudios anteriores están errados. Lo que plantea este trabajo es que el principal factor que produjo la insurrección de la marinería del año 1931. fue el grave deterioro a la "Moral Militar"61 de las fuerzas armadas, que estalló primero en los hombres de mar. Esto comenzó en septiembre de 1924 al violarse la línea de mando. Si tenemos presente que "El principio de autoridad es el eje de la vida militar" 62 , entonces una vez desvirtuado o perdido este eje, se puede esperar cualquier cosa de las instituciones armadas en su conjunto o al menos de un grupo de estas, como fue lo que ocurrió en este caso. Los ejemplos que grafican de mejor forma esta afirmación son cuando las Juntas Militares, compuestas en su mayoria por oficiales jefes y subalternos, disponían a su antojo del cuerpo de generales, o cuando el coronel Ibáñez como ministro de guerra mandaba más que los generales y el mismo caso se puede aplicar para el capitán de fragata Carlos Frödden, cuando como ministro de marina, dirigía la armada por sobre el cuerpo de almirantes. Un manual del ejército señala claramente: "No se puede concebir un ejército sin disciplina y la disciplina militar no es otra cosa que "un estado de orden y conducta entre el personal militar" 63 En estos casos claramente se alteró el orden y la conducta, al no respetarse la jerarquía.

Comprendiendo esto, salta automáticamente a la palestra la siguiente pregunta: Si los generales y almirantes depusieron al presidente Alessandri en septiembre de 1924 y luego en enero de 1925 los oficiales jóvenes depusieron a los generales y almirantes: ¿Por qué ahora en vista de la crisis que vivía el país, no podían ellos los suboficiales, tal vez no tomarse el poder, pero sí por lo menos a través de la presión, hacer valer sus propias peticiones o a lo menos tener la posibilidad de entregar sus propuestas?

A esto hay que sumarle la animadversión cada vez mayor que estaba sintiendo la gente de mar, por sus oficiales, esto se ve avalado por las palabras del historiador Germán Bravo Valdivieso que señala: " ..... en la armada no se había producido un cambio real y efectivo en el trato que se le daba a las tripulaciones como, a esa fecha, se habia hecho en muchas otras marinas. Aún persistían prácticas vejatorias y una desigualdad abismante entre la oficialidad y los suboficiales, sargentos y gente de mar". 64

Como podemos darnos cuenta, la situación en la marina (de las fuerzas armadas y del país en general) era la de un "polvorín", al cual le fattaba una leve "chispa" para explosar, y el año 1931 sucedieron varias "chispas" que desencadenaron el estallido de la sublevación.

Ya hemos visto que el 26 de julio, el general Carlos Ibáñez del Campo deja el poder en manos del presidente del Senado Pedro Opaso Letelier, bajo la mayor animadversión de la ciudadanía hacia las fuerzas armadas y carabineros, Luego, al día siguiente asume Juan Esteban Montero este alto cargo y finalmente tras un par de semanas, ante la renuncia de este último para lanzar su candidatura presidencial, llega al mando de la nación Manuel Trucco. Es precisamente bajo su efímero gobierno, cuando el ministro de hacienda don

\footnotetext{
35. toia, pp. 125-126

34 1 bid, p. 137

60. Balza, Martin Antonio, 2001. Dejo Constancie, Memarias de un General Argentino, Buenos Aires, Editorial Planeta, pp. 89.90.

61. Estado Mayor General del Fjercito, Historia del Ejército de Chife, Colecrion Biblioteca del Oficial, Tomo X. pp. 174-175. La moral militar o moral profesional debe entenderse como una aplicacion de la ética, a la conducta persenal del individuo, en el desempeno de sus actividades profesionales. Asi, entonces, ta moral militar es aquella que se refiere a la moralidad en la actuación profesional militar, cifcunscrita a la aplicación de las normas y principios generales de la moral en los problemas que se presentan.

a2 Ibid, p. 179 .

63 Ejercito de Chile. 1982. Estado Mayor Genenal. Dinerctón de Instrucción. Plan de Lecrión AO-3 Virtuides Militares y Guifa ded Canácter, TT.GG. Instituto Geográfico Militar de Chile.

s. Bravo Valdivieso, Germàn, Op. Cit. p. 103
}

Revista de Historia, año 18, vols. 18-19, 2008-2009, pp. 139-152. 
Pedro Blanquier, el 27 de agosto da a conocer a la luz pública una serie de medidas tendientes a revertir la grave crisis economica que sufría el país, entre las que se contaba una rebaja a los salarios de los empleados públicos que iba desde el $12 \%$ al $30 \%, 10$ que provocó el inmediato descontento de estos, incluida las fuerzas armadas. Dentro de estas, quienes más se sintieron perjudicados, fueron los marinos que prestaban servicio en el acorazado "Almirante Latorre", ya que además de la rebaja recién mencionada y de otra que se había aplicado anteriormente del $10 \%$ durante el gobierno de Ibáñez, también les fue bajada a la mitad la gratificación del $150 \%$ que ganaba este buque, por prestar servicios en Europa, lo que se tradujo en que a estos hombres de mar se les descontaba mensualmente, el anticipo que tuvieron que solicitar para poder cancelar las compras que ya habían hecho en el extranjero. Todo esto, sin mencionar la eliminación de las gratificaciones por especialidad y zonas, entre otras propias del ámbito castrense. ${ }^{65}$ Es por eso que este nueyo anuncio de rebaja cayó como "un balde de agua fría" en el "Latorre". lo que provocó finalmente la explosión. Esta comenzó en el mismo acorazado "Latorre" el martes I de septiembre de 1931 a las 03:30 hrs. ${ }^{66}$ mientras se encontraba atracado en el puerto de Coquimbo junto a los buques de las Escuadras de Instrucción y Evolución. 67

\section{CONCLUSIONES}

La sublevación de la marinería trajo diversas consecuencias al país y a los involucrados. Claramente un hecho de estas características casi no trae consigo resultados positivos, salvo el hecho de que como señaló el general Sáez "Los voluntarios afluyeron de todas partes a los cuarteles. Jóvenes y viejos, ricos y pobres, se disputaron el honor de prestar sus servicios. Era ese un espectáculo reconfortante" 68 Se vivió un reencantamiento, se acrecentó el amor a la Patria, que lamentablemente duro muy poco, pues sólo meses después se levanta "La Republica Socialista" y con esta una seguidilla de cuartelazos.

Para la armada, este hecho representô un profundo golpe que costo años en ser reparado, tanto a nivel de recursos humanos, ya que fueron dados de baja miles de experimentados hombres de mar que fueron reemplazados por otros más bizoños, como a nivel de mentalidad pues los mandos no se esperaban que sus subordinados se levantaran y menos que pudieran controlar todas las reparticiones importantes incluida la escuadra. Además para sofocar la rebelión, se debió recurrir a las otras instituciones armadas.

Debido a lo mismo, estos acontecimientos han sido en general omitidos de la historia naval, ya que salvo los estudiosos de institución, el común del los marinos y de la población del país, desconocen estos sucesos.

Esta investigación ha presentado como incompletos los fundamentos que comúnmente se señala en la historiografía como causales de la insurrección naval, por considerarlos superficiales, ya que una crisis política o una rebaja en los sueldos no bastan para levantar a una institución armada perfectamente organizada y disciplinada. Aquí se afirma que el principal factor que produjo la sublevación. fue la pérdida de la moral militar en las fuerzas armadas, ya que junto con decaer esta, se extravió el sostén de las instituciones castrenses, "la disciplina". Esto se debio al rompimiento de ciertos valores fundamentales en la vida militar como son el principio de autoridad a través de la jerarquía, la confianza y el respeto entre los mandos y sus subalternos. Recordemos que durante el primer gobiemo de Alessandri, los generales depusieron al presidente, para luego ser derrocados a su vez por los oficiales jóvenes y posteriormente el coronel lbánez y el capitán de fragata Frödden dirigieron sus respectivas instituciones por sobre los respectivos cuerpos de generales y almirantes. Además en ese período eran frecuentes los malos tratos de los oficiales con sus subalternos.

Teniendo presente este contexto, basto un nuevo anuncio de rebaja en los sueldos, para provocar la sublevación.

65. Von Schroeders, Edgardo. 1933. El delegado dd Cobierno... p. 10.

o Bravo Valdivieso, Germain, Op. Cat, p. 112

67 Tbid, p. 106

4n. Sdez Morales, Carlos. 1934. Recuentos de un Soldade, Biblioteca Ercilla, Tomo I, pr. 41 


\section{BIBLIOGRAFÍA}

Balza, Martín Antonio. 2001. Dejo Constancia, Memorias de un General Argentino, Buenos Aires, Editorial Planeta.

Bravo Ríos, Leonidas. 1955. Lo que supo un auditor de Guerra, Santiago, Editorial del Pacifico.

Bravo Valdivieso, Germán. 2000. La sublevación de la Escuadra y el periodo revolucionario 1924-1932. Santiago de Chile, Editorial Puerto de Palos, $3^{x}$ Edición.

Cerda, José M. 1934. Relación Histórica de la Revolución de la Armada de Chile, Concepción.

Código de Justicia Militar, Editorial Jurídica de Chile, Novena Edición, 1976, Santiago.

Diario El Sur, septiembre de 1931.

Donoso, Ricardo. 1954. Alessandri Agitador y Demoledor, México. Fondo de Cultura Económica, Colección Tierra Firme, $1^{\circ}$ Edición, Tomo II.

Ejercito de Chile, Estado Mayor General. 1982. Dirección de Instrucción, Plan de Lección AO-3 Virtudes Militares y Guía del Carácter, TT.GG., Santiago, Instituto Geogrăfico Militar de Chile.

Estado Mayor General del Ejército, Historia del Ejército de Chile. Colección Biblioteca del Oficial, Tomo VIII.

Estado Mayor General del Ejército, Historia del Ejército de Chile, Colección Biblioteca del Oficial, Tomo X. Fuenzalida Bade, Rodrigo. 1969. La Armada de Chile desde la Alborada al Sesquicentenario (1813-1968). Armada de Chile.

Guzmán Cortés, Leonardo. 1966. Un Episodio Olvidado de la Historia Nacional (Julio-Noviembre 1931). Santiago, Editorial Andrés Bello.

Lopez Urrutia, Carlos. 1969. Historia de la Marina de Chile. Editorial Andrés Bello.

Sáez Morales, Carlos. 1934. Recuerdos de un Soldado, Biblioteca Ercilla, Tomo I.

Tótoro Taulis, Dauno. 1999. La Cofradía Blindada, Chile Civil y Chile Militar: Trauma y Conflicto, Santiago de Chile, Editorial Planeta, $2^{2}$ Edición.

Vial Correa, Gonzalo. 2001. Historia de Chile, De la Republica Socialista al Frente Popular (1931-1938), Santiago, Editorial Zig-Zag, Volumen V.

Vitale, Luis. 1994. Interpretación Marxista de la Historia de Chile, de la Republica Parlamentaria a la Republica Socialista. De la Dependencia inglesa a la norteamericana (1891-1932), Santiago, Ediciones LOM, Tomo V.

Von Schroeders, Edgardo. 1933. El delegado del Gobiemo y el Motín de la Escuadra, Santiago de Chile, Soc. Imp. y Litografia Universo.

\section{ENTREVISTADOS}

a) Luis Corvalán Lepez el Sábado 26 de enero del 2008, en casa del dirigente, en Santiago.

b) Fernando Quilodran el Viernes 18 de enero del 2008, en la Sede Central del Partido Comunista en Santiago.

c) Ximena Pacheco, conversación telefónica sostenida el Viernes 25 de enero del 2008.

d) Manuel Chamorro Moreno, el miércoles 23 de enero del 2008, en el Departamento de Relaciones Públicas de la Armada, en el Edificio de las Fuerzas Armadas, donde el SOF Chamorro (R) se desempeña. 